Саидов 3.А.

\title{
ГОСУДАРСТВЕННАЯ ЭКОНОМКА КАК ОБЪЕКТ АДМИНИСТРАТИВНО-ПРАВОВОГО ВОЗДЕЙСТВИЯ
}

Аннотация. Предметом статьи являются проблемы правового и организационного характера, связанные с административно-правовым регулированием государственной экономки. Автором подробно проводится теоретико-правовой анализ концепций правового регулирования экономических отношений с позиции административно-правового регулирование как государственного сектора экономики. Рассматриваются авторские позиции относительно понятия государственного регулирования экономики. Основное внимание в статье уделяется разработки методов и методологии административно-правового воздействия на экономические отношения. Кроме того, в статье проводится теоретико-правовой анализ понятий концепций развития права и экономики в современных условиях. Рассматриваются авторские позиции относительно толкования и правовой регламентации данных категорий. Методологическую основу статьи составили современные достижения теории познания. В процессе исследования применялись общефилософрский, теоретический, общефилософские методы (диалектика, системный метод, анализ, синтез, аналогия, дедукция, наблюдение, моделирование), традиционно правовые методы (формально-логический), а также методы, используемые в конкретно-социологических исследованиях (статистические, экспертные оценки и др.). Основной вывод, который сделан по итогам исследования, состоит в том, что в настоящее время для обеспечения правопорядка в срере экономки необходимо совершенствовать формы и методы административно-правового воздействия на государственный сектор российской экономики.Основным вкладом, который сделан авторами в настоящей статье это необходимость развития административно-правового регулирования государственной экономики. Новизна статьи заключается в разработке предложений по развитию форм и методов государственного регулирования экономики, а также создание правовых и организационных гарантий законности в экономике нашей страны.

Ключевые слова: экономика, объект, регулирование, статус, субъект, государство, воздействие, власть, безопасность, бюджет.

Abstract. The research subject is the range of legal and organizational problems of administrative regulation of state economy. The author analyzes the concepts of legal regulation of economic relations from the position of administrative regulation of public sector of the economy. The paper demonstrates the author's positions on the concept of state regulation of the economy. The main attention is paid to the development of methods and methodology of administrative pressure on economic relations. The author analyzes the concepts of development of law and economics in the modern conditions. The article demonstrates the author's positions on the interpretation and legal regulation of these categories. The research methodology comprises the modern achievements in epistemology. The author applies general philosophical and theoretical methods (dialectics, the system method, analysis synthesis, analogy, deduction, observation, modeling), traditional methods of jurisprudence (forma logical) and the methods of specific sociological research (statistical, expert assessments, etc.). The author concludes that at present, in order to ensure law and order in the economic sphere, it is necessary to improve forms and methods of administrative pressure on the public sector of the economy. The author claims that it is necessary to develop administrative regulation of the state economy. The novelty of the research lies in the proposals about the development of forms and methods of state regulation of the economy and about the provision of legal and organizational guarantees of legality in the Russian economy.

Key words: economy, object, regulation, status, subject, state, pressure, authority, safety, budget, economy, object, regulation status, the state, the subject, impact, power, safety, budget.

$\mathrm{T}$ еория, изложенная А. Смитом в его труде «Исследование о природе и причинах богатства народов» [1] придерживалась ультралибе- ральных идей - поддерживающих зарождающейся в эпоху написания данного труда капитализма и была направлена на борьбу с растущей ролью 
государства в экономике. Действительно, на конец XVIII в. пришелся расцвет так называемого меркантилизма в соответствии с которым государства принимали все более активную роль в экономике с целью обеспечения собственной безопасности и пополнения казны [2], что приводило, по словам этого автора, к разорительным для экономики результатам. Так, в частности, данный автор отмечал, что «Великие нации никогда не беднеют изза расточительности и неблагоразумия частных лиц, но они нередко беднеют в результате расточительности и неблагоразумия государственной власти. Весь или почти весь государственный доход в большинстве стран расходуется на содержание непроизводительных элементов. К последним следует отнести всех тех, кто составляет многочисленный и блестящий двор, обширную церковную организацию, большие флоты и армии, в мирное время ничего не производящие, а во время войны не приобретающие ничего, что могло бы покрыть расходы на их содержание... » [3]. Иначе говоря, данный автор призывал к ограничению роли государства в экономике в связи с неэффективностью деятельности последнего, а также отрицательным влиянием его деятельности на экономику в общем.

Напомним, что в соответствии с мнением известного автора роль государства в экономике сводилась к обороне [4]; отправлению правосудия; общественным работам и общественным учреждениям, большая часть из которых, по мнению автора, была необходима для развития торговли [5]. В тоже время, он соглашался с необходимостью участия государства в предоставлении таких услуг как образование [6], что, как следствие, предполагает необходимость осуществления государством не только функций первостепенной необходимости (оборона, поддержание порядка и мира), но также и отдельных функций социальной справедливости. Тем не менее, стоит отметить, что А. Смит оправдывал такую необходимость не столько причинами социальной справедливости, сколько необходимостью совершенствования квалификации рабочей силы с целью повышения конкурентоспособности самой экономики. Аналогичным образом объясняется зарождение государственных систем общего образования и в российском государстве петровской эпохи: «В связи с резким увеличением с начала XVIII в. числа казенных промышленных предприятий и мануфактур встал вопрос об организационно-правовом обеспечении подготовки квалифицированных кадров» [7].

Также как и в других государствах, в России рост государственного вмешательства в экономику и рост самого государственного сектора экономики объяснялся необходимостью поддержания обороноспособности. Так, например, Богомазов
В.В. определяет в качестве основной причины централизации экономических функций государства «...постоянная внешняя опасность, которую можно отражать лишь при наличии сильного войска...»[8]. Это вполне объяснимо если принять во внимание тот факт, что на рубеже XVII-XVIII веков 78 \% бюджета российского государства составляли военные расходы [9]. Таким образом, как в России, так и в других государствах первыми государственными предприятиями стали предприятия в сфере добычи полезных ископаемых (в первую очередь по добыче металлов, необходимых для создания оружия) и их обработки с целью обеспечения обороноспособности государства. Напомним, что именно такое развитие трудоёмких и затратных сфер промышленности, не представляющих интереса для частного капитала, потребовало серьёзных затрат на создание первых, именно государственных, мануфактур в кораблестроительной и сталелитейной сферах, а также создания на государственном уровне первых ведомств по управлению такими предприятиями [10].

Стоит отметить, что рост роли государства в экономике не объяснялся исключительно причинами поддержания мира, безопасности и обороноспособности государства. Позднее, государство наделило себя рядом функций, выполняемых ранее различными социальными институтами не имеющими напрямую отношения в государству (церковь, аристократия, община и т.п.). Так, например, если обеспечение здравоохранения (защита от эпидемий) и образование изначально предоставлялись населению религиозными институтами, то в процессе конкуренции государства (абсолютной монархии) и церкви за власть данные функции были возложены на само государство, что, как следствие, привело к расширению его регулятивных функций и аппарата. Этот процесс был довольно критично описан современным французским философом Мишелем Фуко [11], который негативно отнесся к данному процессу, критикуя рост государственного аппарата и его контрольных функций, ограничивающих свободу индивидов и отрицательно сказывающихся, в том числе на свободе коммерческой деятельности [12]. Стоит отметить, что роль государства в экономико-социальной сфере росла не только за счет и заполнения различных сфер жизнедеятельности посредством создания государственных учреждений (больниц, школ и т.п.). Действительно, расширение функций государства сопровождалось расширением его аппарата, что потребовало организационно-правового регулирования трудовых отношений в государственном секторе экономики, совершенствования налоговой системы и усиления налогового бремени и т.п. 


\section{Административное и муниципальное право 3 (99) • 2016}

Проблема финансового обеспечения государственного аппарата сопровождалась развитием налоговой системы, а также развитием государственного сектора промышленности, направленного уже не столько на обеспечение обороноспособности страны, сколько на получение прибыли и, в первую очередь, предоставления социальных услуг населению. Так, например, именно с целью получения прибыли стали появляться спиртоводочные и табачные государственные монополии, а также государственные предприятия в сфере сельского хозяйства (зернохранилища, элеваторы и т.п.). Тем не менее - по крайней мере в дореволюционной России - основными представителями государственного сектора экономики XIX в. оставались предприятия оборонного сектора (сталелитейные, судостроительные и т.п.) [13].

Современные экономико-социальные факторы стимулировали создание государственных предприятий в новых секторах экономики.

Так, например, развитие транспорта и в частности железных дорог, являющихся необходимым средством развития и диверсификации экономики, а также увеличения товарооборота, в связи с дороговизной строительства железнодорожных инфраструктур в принципе не могли осуществиться без участия государства. Как следствие, чтобы не отстать от западных держав, а также стимулировать развитие Урала и западной Сибири «ведущим направлением организационно-правового регулирования государственного сектора в экономике страны второй половины XIX в. является деятельность казны в железнодорожном хозяйстве» [14]. Иначе говоря, данный сектор государственной экономики образовался в связи с невозможностью частного капитала удовлетворить потребности развития экономики.

Аналогичным образом развивался сектор почтовых услуг и связи, изначально использовавшийся исключительно для военных целей, а в последствии сыгравший немаловажную роль в развитии хозяйственных отношений. Более того, сегодня, с появлением сети Интернет хозяйственная деятельность стала развиваться именно в рамках коммуникационных технологий, что свидетельствует о высоком значении услуг связи для развития экономики. В тоже время, на начальном периоде становления почтово-телеграфных услуг сложность и дороговизна инфраструктур связи, а также их невысокая рентабельность потребовали участия государства в их становлении и развитии. В науке отмечалось по данному поводу, что «деятельность в сфере связи в России насчитывает многовековую историю развития. На ранних этапах широкое распространение получили услуги почтовой связи, которые не требовали сложного технического обе- спечения. И только во второй половине XIX в. в связи с внедрением новых информационных технологий создаются принципиально новые сложные способы передачи информации - телеграф и телефон» [15], потребовавшие серьезных инвестиций в развитие инфраструктуры.

Наконец, стоит привести наиболее актуальный на сегодняшний день пример, который ярко свидетельствует о причинах развития государственного сектора экономики - энергетику. Энергетика, в связи с тем, что она стала в современном мире основным фактором развития экономики любого государства, вполне обосновывает необходимость вмешательства государства в данную отрасль посредством различных форм [16]. Контроль энергетической отрасли со стороны государства наиболее актуален для Российской Федерации, где более половины федерального бюджета состоит из прямых и косвенных нефтегазовых доходов, что, таким образом, позволяет говорить о том, что государственный контроль данной сферы экономики является гарантом безопасности и даже выживаемости российской экономики.

Таким образом, насколько бы ни были критичны размышления А. Смита по поводу государственного сектора экономики, очевидно, что они соответствовали лишь реалиям эпохи в которую они были написаны (конец XVIII века). Действительно, если в эту эпоху единственной значимой функцией государства было обеспечение мира и безопасности, то постепенное сокращение значимости классических социальных институтов (семьи, общины, аристократии, церкви и т.п.) в современном мире, осуществившееся под воздействием различных экономико-социальных факторов (урбанизация, индустриализация, миграция населения и т.п.), а также развитие научно-технического прогресса выразилось в переносе таких функций на плечи государства, а также в появлении новых функций государства в сфере экономики. Как следствие, функции и аппарат государства, а также налоговое бремя, необходимое для его обеспечения выросли в пропорциональной прогрессии, что отразилось и на росте государственного сектора экономики. Как отмечается в науке «рыночный механизм не срабатывает, когда достигаемый полезный эффект не поддается быстрой и точной оценке со стороны потребителя. Это характерно, в частности, для здравоохранения и народного образования. В ряде областей, особенно в фундаментальной науке, в принципе невозможно строить экономические отношения на основе оплаты потребителем конкретных результатов ...Реальный, эффективно функционирующий рынок отсутствует и там, где существует так называемая естественная монополия...» [17]. Как следствие, государственный 
сектор экономики рос и продолжает пополняться новыми сферами жизнедеятельности.

Развитие государственного сектора в многочисленных отраслях экономики отразилось и на институциональной структуре исполнительной власти, которая является инструментом обеспечения государственного вмешательства в экономику. Помимо ее усложнения, которое мы можем проследить на примере структуры Правительства, министерств и ведомств можно также констатировать и расширение сферы вмешательства государства в экономику. Действительно, если изначально структура министерств российского государства состояла из 9-10 коллегий, из которых лишь две - три касались сектора экономики, а две именно государственного сектора экономики, то сегодня ситуация изменилась кардинальным образом. Так, сегодня, структура федеральных органов власти не только усложнилась, но и разрослась «поглотив» новые сферы жизнедеятельности, в том числе и экономики. Сегодня мы обнаружим в их структуре не только министерства, ответственные за государственный сектор экономики, эквиваленты которых мы могли обнаружить в структуре органов исполнительной власти практически во все периоды исторического развития российского государства (так, например, эквивалентом Берг- и Мануфактур- коллегий сегодня можно признать Министерство промышленности). Действительно, в нынешней структуре высших федеральных органов исполнительной мы обнаружим министерства и ведомства которых не существовало ранее и которые были образованы в связи с ростом государственного сектора экономики (например Министерство энергетики; Министерство транспорта и связи, Министерство здравоохранения и т.п.) В компетенцию последних входит в частности управление государственными предприятиями и учреждениями в соответствующей сфере жизнедеятельности, т.е. управление государственным сектором экономики. Таким образом, новые экономико-социальные факторы современного мира стимулировали вмешательство государства в новые секторы экономики, что отразилось и на диверсификации структуры высших органов государственной власти.

Картина исторического развития государственного сектора экономики в различных государствах практически идентична. На протяжении всего XIX и XX в. государственный сектор экономки рос, лишь в отдельных государствах испытывая разгрузку посредством приватизаций. Государственный сектор экономики постепенно пополнялся новыми отраслями в различные периоды развития современного государства там, где его значение было фундаментальным для безопасно- сти государства и экономики в целом, а частные инициативны, не могли в полной мере эффективно способствовать развитию той или иной сферы экономики. Если на сегодняшний день между различными государствами существуют различия в подходах к государственному вмешательству в экономику в целом, то государственный сектор любого государства сосредоточен в основном в таких отраслях как: услуги связи; электроэнергетика; газовая промышленность; нефтеперерабатывающая промышленность; угольная промышленность; сталелитейная промышленность; железнодорожный транспорт и т.п. Существенные различия между государствами мы можем наблюдать лишь в доле участия государства в том или ином секторе экономики, которая варьируется от незначительных показателей, приходящихся на государственный сектор той или иной отрасли экономики в либеральных государствах (например в США или Японии) до значительных долей, приходящихся на государственные предприятия и учреждения в государствах с эгалитарным социально-политическим устройством (например в России и европейских государствах) [18]. Иначе говоря, в современном мире речь идет не о необходимости вмешательства государства в тот или иной сектор экономики - необходимость которой сегодня не оспаривается практически никем - a, скорее, об уровне такого вмешательства [19].

В свою очередь, как только тот или иной сектор экономики, где государственное участие было исключительным (монополия) или доминирующим, не требовал государственного вмешательства, большинство государств капиталистического мира предпочитали и предпочитают прибегать к его приватизации (исключением остаются те сферы жизнедеятельности где, например, вопросы безопасности требуют повышенного участия государства, а также там, где мы сталкиваемся с социальными обязательствами государства). Это объяснялось тем, что в рамках государственного сектора экономики управленческие процессы являются менее эффективными, так как государственные предприятия и учреждения в принципе не преследуют извлечения выгоды и являются обузой для государственного бюджета.

Сложности в сочетании государственного и частного сектора в рамках определенной сферы рыночной экономики, где не существует исключительной монополии государства, возникли в России на начальном этапе становления рыночной экономики. Проблемным в частности стал сектор образования, сомнения, в необходимости перехода которого в частный сектор экономики воспрепятствовали его приватизации. В итоге, на сегодняшний день в секторе образования, как и в 


\section{Административное и муниципальное право 3 (99) • 2016}

большинстве других сфер экономики, сложилась соответствующая рыночной экономике ситуация, где государственный сектор экономики существует в связи с наличием социальных обязательств государства (в данном случае в связи с необходимостью обеспечения населения доступным и бесплатным образованием), тогда как частный сектор экономики образовался в связи с закреплением свободы экономической деятельности и, как следствие, возможностью предоставления аналогичных услуг частными субъектами экономики. Таким образом, сегодня в соответствии с принципами рыночной экономики в различных сферах экономики сосуществуют два сектора экономики: государственный и частный.

Процессы приватизации и национализации оказывают непосредственное влияние на сектор государственной экономики, так как от него зависит доля государственного участия в экономике, т.е. объем государственного вмешательства в экономику, что является наиболее ярким выражением административно-правового регулирования государственного сектора экономики. В тоже время отдельные сферы экономико-социальной жизнедеятельности практически не подвержены процессам приватизации, так как рассматриваются - как в России, так и в других государствах - как сектор входящий в обязанность социального государства (здравоохранение, начальное и среднее образование и т.п.). В науке отмечается, что «особенностью становления госсектора экономики в России является включение в него не только госпредприятий, но и государственных учреждений, которые традиционно не входят в госсектор развитых стран» [20]. Как следствие, в отличие от зарубежной науки административного права, в российской науке в государственный сектор экономики включаются не только государственные предприятия strico sensu, т.е. индустриальные (промышленные) субъекты хозяйственной деятельности и относимые к коммерческому сектору экономики, но и государственные учреждения, которые относятся к некоммерческому сектору экономики.

Стоит отметить, что как в зарубежной, так и в российской науке не существует единства в понимании сущности государственного сектора экономики. Более того, ни одно из них не обладает достаточным уровнем конкретики, что в то же время можно объяснить его довольно объемным, абстрактным характером. Так, например, наименее удовлетворительными, на наш взгляд, являются понятия государственного сектора экономики которые были даны Я. Корнай [21], а также Ю.И. Хаустова [22].

Более удовлетворительны - вследствие конкретики - понятия В.П. Орешкина и Л.И. Якобсона.
Так, первый предлагает в понятие государственного сектора экономики включить помимо государственных учреждений и предприятий акционерные общества с закреплением в собственности государства контрольного пакета акций и акционерные общества «с пакетом государственных акций, позволяющих оказывать существенное влияние на управление» [23]. Л.И. Якобсон считает, что государственным сектором экономики является «совокупность ресурсов, находящихся в непосредственном распоряжении государства, образуют общественный сектор хозяйства...» среди которых не только предприятия и учреждения, находящиеся в собственности государства, но и денежные средства, формируемые в процессе функционирования государственных финансов [24].

Наибольшим интересом, на наш взгляд, обладают понятия государственного сектора, определяющие его через понятие публичной, т.е. государственной (а также субъекта федерации и муниципальной) собственности [25]. Данный подход верен с юридической точки зрения, так как собственность в отличие от других довольно абстрактных понятий обладает юридической ценностью и конкретикой, а понятие собственности обладает юридическим статусом.

В тоже время, в связи с разнородностью научных понятий государственного сектора экономики, наиболее прагматичен, на наш взгляд, подход основанный на понятии, предоставленном позитивным правом. Действительно, если отстраниться о сугубо научных подходов к определению государственного сектора экономики и идентифицировать его с помощью позитивного права, то мы обнаружим, что к данному сектору экономики следует относить и учреждения и даже предприятия социального сектора экономики. Так, в соответствии с постановлением Правительства Российской Федерации от 4 января 1999 г. «0 прогнозе развития государственного сектора экономики» следует «...к хозяйствующим субъектам государственного сектора экономики относить:

- государственные унитарные предприятия, в том числе казенные;

- $\quad$ государственные учреждения;

- хозяйственные общества, в уставном капитале которых более 50 \% акций (долей) находятся в государственной собственности;

- хозяйственные общества, в уставном капитале которых более 50 \% процентов акций (долей) находятся в собственности хозяйственных обществ, относящихся к государственному сектору экономики».

Таким образом, подход выбранный Правительством России к определению понятия государственного сектора экономики строиться в 
основном на понятии собственности, а именно государственной (публичной) собственности. Данное понятие было заимствовано в науке и относится различными авторами к, так называемому, «ресурсному подходу» определения государственного сектора экономики. Так, например, Е.В. Балацкий и В.А. Конышев определяют государственный сектор экономики в соответствии с понятием позитивного права как «совокупность государственных предприятий, организаций и учреждений» или «совокупность хозяйствующих субъектов, управление оперативной производственной деятельностью которых осуществляется государством» [26].

Следует обратить внимание на ряд особенностей административно-правового регулирования указанных субъектов экономики.

Административно-правовое регулирование государственных учреждений и предприятий отличается определенными особенностями в сравнении с классическими принципами регулирования частных субъектов экономической деятельности, которые в принципе обладают автономией организации, функционирования и ведения хозяйственной деятельности. Иначе говоря, несмотря на единство сферы экономической деятельности, аналогичность производимых услуг и/или товаров, административно-правовое регулирование субъектов государственного и частного сектора серьёзно различаются. В принципе, административно-правовое регулирование субъектов государственного сектора экономики можно определить как аналогичное тем принципам административно-правового регулирования, которые используются в отношении других субъектов публичного права (органов государственной власти).

Подтверждение особенностей статуса и правового регулирования субъектов государственного сектора экономики мы можем обнаружить в ГК РФ. Действительно, в соответствии со ст. 113 ГК РФунитарным предприятием, в форме которого действуют государственные и муниципальные предприятия, «...признается коммерческая организация, не наделенная правом собственности на закрепленное за ней собственником имущество. Имущество унитарного предприятия является неделимым и не может быть распределено по вкладам (долям, паям), в том числе между работниками предприятия». Иначе говоря, субъекты государственного сектора экономики (в данном случае унитарные предприятия), в отличие от частноправовых субъектов экономики, обладают сокращенной автономией в распоряжении находящимся у ним имуществом. Более того, в соответствии с Федеральным законом от 14 ноября 2002 г. «0 государственных и муниципальных унитарных предприятиях» свобода деятельности руководства унитарных предпри- ятий значительным образом ограничена правами собственника имущества унитарного предприятия (ст. 20). Таким образом, в отличие частноправовых субъектов хозяйственной деятельности, субъекты государственного сектора экономики ограничены в своих действиях правами собственника - т.е. государства, субъекта федерации или муниципального образования.

В науке выделяются и другие особенности административно-правового регулирования субъектов государственного сектора экономики. Так, например, Т.В. Капелько пишет: «..особенностями правового положения субъектов публичной собственности являются:

- наличие у них властных полномочий, позволяющих им принимать нормативные акты, регламентирующие порядок осуществления принадлежащего им права собственности;

- $\quad$ реализация этого права в публичных, общественных интересах» [27]. Иначе говоря, административно-правовое регулирование субъектов государственного сектора экономики осуществляется собственниками, которые располагают властными полномочиями, позволяющими им принимать нормативные акты, регламентирующие деятельность этих субъектов и реализуют это административноправовое регулирование в публичных общественных интересах.

Стоит отметить, что количество особенностей административно-правового регулирования субъектов государственного сектора экономики не ограничивается только что указанными. А их существование объясняется как необходимостью защиты государственной собственности от уголовно наказуемых деяний; явным протекционизмом; необходимостью противодействия коррупции, а также рядом других факторов [28]. Обратим внимание лишь на некоторые из актов государственной власти установивших различные особенности административно-правового регулирования государственного сектора экономики.

- Указ Президента РФ от 18 августа 1996 г. «О мерах по защите прав акционеров и обеспечению интересов государства как собственника и акционера». Данный акт появился на заре становления рыночной экономики и был направлен, как свидетельствует его название, на защиту государственной собственности от недобросовестных действий при слиянии и поглощении предприятий, что пришлось на период расцвета всеобщей приватизации в России. Здесь в частности устанавливается ряд особых положений касающихся: принятия решений в рамках руководящих органов акционерных обществ, собственником которых (в 
том числе и частичным) является государство; особенностей процедуры выпуска дополнительных акций таких предприятий; особенностей принятия решений по выплате дивидендов и т.п.

- Распоряжение Президента РФ 114-рп «Об утверждении Положения об определении пообъектного состава федеральной, государственной и муниципальной собственности и порядке оформления прав собственности». Данный акт, в частности, установил особый порядок оформления прав собственности, регистрации сделок купли-продажи государственного имущества, гласности и отчетности действий органов государственной власти (соответствующих комитетов по управлению государственным имуществом) и т.п.

- Постановление Правительства РФ от 23 января 2003 г. «0 порядке управления находящимися в федеральной собственности акциями открытых акционерных обществ и использования специального права Российской Федерации на участие в управлении открытыми акционерными обществами («золотой акции»)». Данный акт устанавливает особенности осуществления прав государства-собственника в отношении открытых акционерных обществ и, в частности, устанавливает особенности голосования в руководящих органах данных обществ. Аналогичным актом, но касающимся не управления акционерными обществами, а унитарными предприятиями, можно признать постановление Правительства Российской Федерации от 3 декабря 2004 г. «О полномочиях федеральных органов исполнительной власти по осуществлению прав собственника имущества федерального государственного унитарного предприятия», где также устанавливаются особенности осуществления прав государствасобственника в отношении данной категории субъектов государственного сектора.

Приведенные примеры представляют лишь малую долю нормативных актов регулирующих прядок административно-правового регулирования деятельности субъектов государственного сектора. Более того, даже если не включать в государственный сектор экономики такие объекты государственной собственности как недра, бюджет, полезные ископаемые т.п. [29], а остановиться лишь на тех субъектах государственного сектора экономики, которые подпадают под понятие данное постановлением Правительства Российской Федерации от 4 января 1999 г. № 1 (см. подробнее выше), то очевидно, что и в этом случае количество субъектов данного сектора практически не ограничено. Это объясняет сложности их инвентариза- ции и их административно-правового регулирования. Как следствие, на институциональном уровне органов государственной власти (как федеральной, так и субъектов федерации и муниципальной власти) был создан ряд органов, в задачи которых вошло как нормативно-правовое регулирование функционирования данных субъектов, так и, собственно, регулирование вопросов осуществления прав собственника, т.е. владения, пользования и распоряжения.

В соответствии с постановлением Правительства Российской Федерации от 5 июня 2008 г. «0 Федеральном агентстве по управлению государственным имуществом» основным органом государственной власти, в общую компетенцию которого входит управление государственным имуществом является Федеральное агентство по управлению государственным имуществом. Данное агентство осуществляет функции по управлению федеральным имуществом, осуществляет полномочия собственника в отношении данного имущества; осуществляет полномочия государственного финансового контрольного органа; осуществляет проверку использования этого имущества и т.п. Стоит также отметить, что данный орган исполнительной власти, находящийся в ведении Министерства экономического развития Российской Федерации, осуществляет свою деятельность и через свои территориальные органы и подведомственные организации. Такая широкая и разветвленная структура данного органа исполнительной власти свидетельствует о значительном количестве субъектов государственного сектора экономики подконтрольных ему, т.е. о значительности государственного сектора экономики.

Более того, данное агентство не является единственным органом государственной власти, выполняющим функции административно-правового регулирования государственного сектора экономики. Ряд министерств, ведомств и агентств осуществляет подобные функции в отношении определённых субъектов государственного сектора экономики или даже категорий таких субъектов. Действительно, помимо Правительства РФ, которое «...осуществляет управление федеральной собственностью...» и Министерства экономического развития РФ, которое осуществляет такое управление с помощью департамента имущественных отношений и подотчетного ему Федерального агентства по управлению имуществом, практически при каждом министерстве существует структура ответственная за те или иные объекты государственного сектора экономики. В данном отношении в науке административного права отмечается, что «реализация права государства на объекты собственности достигается через функци- 
онирование системы управления государственной собственностью, под которой понимается совокупность органов государственной и исполнительной власти, территориальных органов (агентств) Фе- дерального органа по управлению федеральным имуществом (Росимущества), органов управления собственностью субъектов РФ и объектов государственной собственности» [30].

\section{Библиография:}

1. Смит А. Исследование о природе и причинах богатства народов. - М., 2007.

2. Талапина Э.В. О публичном экономическом праве // Журнал российского права. - 2004. - № 7. - С. 85.

3. Смит А. Исследование о природе и причинах богатства народов. - М., 2007. - С. 349

4. Гоббс Т. Левиафан, или Материя, форма и власть государства церковного и гражданского. - M., 2001. гл. XVII).

5. Гоббс Т. Левиафан, или Материя, форма и власть государства церковного и гражданского. - M., 2001. гл. XVII).

6. Гоббс Т. Левиафан, или Материя, форма и власть государства церковного и гражданского. - M., 2001. гл. XVII).

7. Капелько Т.В. Административно-правовое регулирование государственного сектора экономики: Дис. ... канд. юрид. наук. - М., 2012. - С. 27.

8. Богомазов Г.Г. Государственное и частное предпринимательство в России: соотношение и тенденции развития // Вестник Санкт-Петербургского университета. Сер.5. 1998. Вып. 3. - С. 34.

9. Павленко Н.И. Развитие металлургической промышленности России в первой половине XVIII века. - M., 1953. - C. 205.

10. Речь идет о создании Берг-коллегии и Мануфактур-коллегии, которым соответственно вменялось в обязанность управление «Рудокопные заводы и все прочие ремесла и рукоделия и заводы оных и размножение, при том же и артиллерия». Данная фраза Указа от 11 (22) декабря 1717 г. «Об управлении во всех коллегиях и в губерниях дел с 1720 г. по новому порядку и о разделении дел между коллегиями» свидетельствует на наш взгляд о явной направленности промышленности тех лет на обеспечение обороноспособности государства. См.: Полн. Собр. Зак., Т. V., № 3255

11. Фуко М. Надзирать и наказывать. Рождение тюрьмы. - М., 1999.

12. A. de Tocqueville, Ancien régime et la Révolution, Gallimard, 1967, p. 98 et s.

13. Шацилло К.Ф. Государство и монополии в военной промышленности России (конец XIX - 1914 г.). - М., 1992. - С. 30.

14. Капелько Т.В. Административно-правовое регулирование государственного сектора экономики: Дис. ... канд. юрид. наук. - М., - 2012.

15. Калинина А.С. Правовые основы лицензирования в сфере связи: Дис...канд. юрид. наук. - М., 2009. - С. 5.

16. Миллер Н.Е. Государственная энергетическая политика в постсоветской России: этапы и особенности развития. Дис.... канд. полит. наук. - Уфа, 2009. - С. 4.

17. Якобсон Л.И. Некоммерческий сектор экономики: проблемы правового регулирования // Государство и право. 1992. - № 3. - С. 41.

18. Ясин Е. Опыт развитых стран по управлению государственным сектором в экономике // Вопросы экономики. 2008. - № 6. - С. 13.

19. Талапина Э.В. Государственный сектор в экономике зарубежных стран // Государство и право. - 2009. - № 11. - С. 73.

20. Капелько Т.В. Административно-правовое регулирование государственного сектора экономики: Дис. ... канд. юрид. наук. - М., 2012. - С. 67

21. Корнай Я. Путь к свободной экономике: (Страстное слово в защиту экономических преобразований) Пер. с англ. / Предисловие Н.Я. Петракова. - М., 1990. - С.18.

22. Экономическая теория: Учебник / Под ред. Ю.И. Хаустова.-Воронеж: Изд-во Воро-неж.гос. ун-та, 2003.-С. 165.

23. Государственное регулирование национальной экономики / Под ред. В.П. Орешкина. - М., 2000. - С. 44.

24. Якобсон Л.И. Государственный сектор экономики. Экономическая теория и политика. - М., 2000. - С. 24.

25. Бабашкина А.М. Государственное регулирование национальной экономики. - М., 2006. - С.71.

26. Балацкий Е.В., Конышев В.А. Российская модель государственного сектора экономики. - М., 2005. - С. 9.

27. Капелько Т.В. Административно-правовое регулирование государственного сектора экономики: Дис. ... канд. юрид. наук. - М., 2012. - С. 88.

28. Лунеев В.В. Проблемы противодействия экономической преступности // Государство и право. - 2014. - № 2. - С. 32.

29. И.С. Викторов, Д.Г. Алексеева, Н.Д. Бут, Д.А. Звягинцев, Б.И. Шалыгин, Государственная собственность в Российской Федерации. Правовое регулирование, правоприменительная и прокурорская практика. - М., 2004. - 571 с.

30. Капелько Т.В. Административно-правовое регулирование государственного сектора экономики: Дис ... канд. юрид. наук. - М., 2012. - С. 117.

31. Саидов 3.А. Административно-правовой статус субъектов экономических отношений и проблемы его реализации // Полицейская деятельность. - 2015. - 3. - С. 141 - 155. DOI: 10.7256/2222-1964.2015.3.15569.

32. Пронин Э.А. Экономическая безопасность государства: истоки и концептуальные связи // Полицейская деятельность. - 2015. - 3. - С. 156 - 163. DOI: 10.7256/2222-1964.2015.3.15584.

\section{References (transliterated):}

1. Smit A. Issledovanie o prirode i prichinakh bogatstva narodov. - M., 2007.

2. Talapina E.V. O publichnom ekonomicheskom prave // Zhurnal rossiiskogo prava. - 2004. - № 7. - S. 85.

3. Smit A. Issledovanie o prirode i prichinakh bogatstva narodov. - M., 2007. - S. 349

4. Gobbs T. Leviafan, ili Materiya, forma i vlast' gosudarstva tserkovnogo i grazhdanskogo. - M., 2001. gl. XVII). 


\section{Административное и муниципальное право 3 (99) • 2016}

5. Gobbs T. Leviafan, ili Materiya, forma i vlast' gosudarstva tserkovnogo i grazhdanskogo. - M., 2001. gl. XVII).

6. Gobbs T. Leviafan, ili Materiya, forma i vlast' gosudarstva tserkovnogo i grazhdanskogo. - M., 2001. gl. XVII).

7. Kapel'ko T.V. Administrativno-pravovoe regulirovanie gosudarstvennogo sektora ekonomiki: Dis. ... kand. yurid. nauk. M., 2012. - S. 27.

8. Bogomazov G.G. Gosudarstvennoe i chastnoe predprinimatel'stvo v Rossii: sootnoshenie i tendentsii razvitiya // Vestnik Sankt-Peterburgskogo universiteta. Ser.5. 1998. Vyp. 3. - S. 34.

9. Pavlenko N.I. Razvitie metallurgicheskoi promyshlennosti Rossii v pervoi polovine XVIII veka. - M., 1953. - S. 205.

10. Rech' idet o sozdanii Berg-kollegii i Manufaktur-kollegii, kotorym sootvetstvenno vmenyalos' v obyazannost' upravlenie «Rudokopnye zavody i vse prochie remesla i rukodeliya i zavody onykh i razmnozhenie, pri tom zhe i artilleriya». Dannaya fraza Ukaza ot 11 (22) dekabrya $1717 \mathrm{~g}$. «Ob upravlenii vo vsekh kollegiyakh i v guberniyakh del s $1720 \mathrm{~g}$. po novomu poryadku i o razdelenii del mezhdu kollegiyami» svidetel'stvuet na nash vzglyad o yavnoi napravlennosti promyshlennosti tekh let na obespechenie oboronosposobnosti gosudarstva. Sm.: Poln. Sobr. Zak., T. V., № 3255

11. Fuko M. Nadzirat' i nakazyvat'. Rozhdenie tyur'my. - M., 1999.

12. A. de Tocqueville, Ancien régime et la Révolution, Gallimard, 1967, p. 98 et s.

13. Shatsillo K.F. Gosudarstvo i monopolii v voennoi promyshlennosti Rossii (konets XIX - 1914 g.). - M., 1992. - S. 30.

14. Kapel'ko T.V. Administrativno-pravovoe regulirovanie gosudarstvennogo sektora ekonomiki: Dis. ... kand. yurid. nauk. M., - 2012.

15. Kalinina A.S. Pravovye osnovy litsenzirovaniya v sfere svyazi: Dis...kand. yurid. nauk. - M., 2009. - S. 5.

16. Miller N.E. Gosudarstvennaya energeticheskaya politika v postsovetskoi Rossii: etapy i osobennosti razvitiya. Dis.... kand. polit. nauk. - Ufa, 2009. - S. 4.

17. Yakobson L.I. Nekommercheskii sektor ekonomiki: problemy pravovogo regulirovaniya // Gosudarstvo i pravo. - 1992. № 3. - S. 41.

18. Yasin E. Opyt razvitykh stran po upravleniyu gosudarstvennym sektorom v ekonomike // Voprosy ekonomiki. - 2008. № 6. - C. 13.

19. Talapina E.V. Gosudarstvennyi sektor v ekonomike zarubezhnykh stran // Gosudarstvo i pravo. - 2009. - № 11. - C. 73.

20. Kapel'ko T.V. Administrativno-pravovoe regulirovanie gosudarstvennogo sektora ekonomiki: Dis. ... kand. yurid. nauk. M., 2012. - S. 67

21. Kornai Ya. Put' k svobodnoi ekonomike: (Strastnoe slovo v zashchitu ekonomicheskikh preobrazovanii) Per. s angl. / Predislovie N.Ya. Petrakova. - M., 1990. - S.18.

22. Ekonomicheskaya teoriya: Uchebnik / Pod red. Yu.I. Khaustova.-Voronezh: Izd-vo Voro-nezh.gos. un-ta, 2003.-S. 165.

23. Gosudarstvennoe regulirovanie natsional'noi ekonomiki / Pod red. V.P. Oreshkina. - M., 2000. - S. 44.

24. Yakobson L.I. Gosudarstvennyi sektor ekonomiki. Ekonomicheskaya teoriya i politika. - M., 2000. - S. 24.

25. Babashkina A.M. Gosudarstvennoe regulirovanie natsional'noi ekonomiki. - M., 2006. - S.71.

26. Balatskii E.V., Konyshev V.A. Rossiiskaya model' gosudarstvennogo sektora ekonomiki. - M., 2005. - S. 9.

27. Kapel'ko T.V. Administrativno-pravovoe regulirovanie gosudarstvennogo sektora ekonomiki: Dis. ... kand. yurid. nauk. M., 2012. - S. 88.

28. Luneev V.V. Problemy protivodeistviya ekonomicheskoi prestupnosti // Gosudarstvo i pravo. - 2014. - № 2. - S. 32.

29. I.S. Viktorov, D.G. Alekseeva, N.D. But, D.A. Zvyagintsev, B.I. Shalygin, Gosudarstvennaya sobstvennost' v Rossiiskoi Federatsii. Pravovoe regulirovanie, pravoprimenitel'naya i prokurorskaya praktika. - M., 2004. - $571 \mathrm{~s}$.

30. Kapel'ko T.V. Administrativno-pravovoe regulirovanie gosudarstvennogo sektora ekonomiki: Dis ... kand. yurid. nauk. M., 2012. - S. 117.

31. Saidov Z.A. Administrativno-pravovoi status sub"ektov ekonomicheskikh otnoshenii i problemy ego realizatsii // Politseiskaya deyatel'nost'. - 2015. - 3. - C. 141 - 155. DOI: 10.7256/2222-1964.2015.3.15569.

32. Pronin E.A. Ekonomicheskaya bezopasnost' gosudarstva: istoki i kontseptual'nye svyazi // Politseiskaya deyatel'nost'. 2015. - 3. - C. 156 - 163. DOI: 10.7256/2222-1964.2015.3.15584. 